\title{
Classroom Implementation of Instructional Modules Developed by Teachers during Engineering RET Programs: A Follow-up Study
}

\section{Dr. Linda S Hirsch, New Jersey Institute of Technology}

LINDA S. HIRSCH is the Program Evaluator for the Center for Pre-College programs. She has a doctoral degree in educational psychology with a specialty in psychometrics and a Masters degree in statistics. She has been involved in all aspects of educational and psychological research for over 20 years. Dr. Hirsch has extensive experience conducting longitudinal research studies and is proficient in database management, experimental design, instrument development, psychometrics and statistical programming.

\section{Dr. Howard S. Kimmel, New Jersey Institute of Technology}

HOWARD KIMMEL is Professor-Emeritus of Chemical Engineering and Retired Executive Director of the Center for Pre-College Programs at New Jersey Institute of Technology. Dr. Kimmel is currently providing his services on a part-time basis as a Special Assistant for Teacher Training and Curriculum Development with a focus on alignment of teaching practices with the Common Core State Standards and the Next Generation Science Standards. He has spent almost forty years designing and implementing professional development programs, curricula, and assessment of student learning for K-12 teachers in STEM. At the college level, he collaborates on projects exploring teaching methodologies and assessment strategies in undergraduate courses in the sciences, engineering, and computer science. Dr. Kimmel has received numerous awards in recognition of his service, including: ASEE 1985 Vincent Bendix Minorities in Engineering Award, and ASEE CENTENNIAL MEDALION for "Significant Lasting Impact on Engineering Education," 1993. The NJIT Foundation Overseers Public and Institute Service Award, 1981 (First Recipient) and in 2005; and the Allan R. Cullimore Distinguished Service Award (NJIT) for 1991.

\section{Dr. John D. Carpinelli, New Jersey Institute of Technology}

Dr. John D. Carpinelli is a Professor of Electrical and Computer Engineering at the New Jersey Institute of Technology. He has served as coordinator of activities at NJIT for the Gateway Engineering Education Coalition and as a member of the Coalition's Governing Board. He previously chaired NJIT's Excellence in Teaching Awards Committee and is Past Chair of the University Master Teacher Committee. 


\section{Classroom Implementation of Instructional Modules Developed by Teachers During Engineering RET Programs: A Follow-up Study Research to Practice: Strand 1}

Most K-12 teachers in the United States have not been trained to incorporate engineering and technology topics into classroom lessons and there is a lack of high-quality curricular materials in these areas. The National Science Foundation's Research Experiences for Teachers (RET) have been developed as an effective means to expose secondary school science teachers to the world of research and introduce them to the field of engineering. The ultimate goal of most RET programs is for teachers to be able to synthesize their research experience and integrate their new skills and knowledge into an instructional module they can implement in their classroom. Bringing the concepts of scientific inquiry and engineering into K-12 classroom is especially important with the introduction of the Next Generation Science Standards. Although reports on the results of most RET programs appear to be positive in terms of teacher satisfaction, gaining research skills and improved content knowledge about engineering, few programs have reported on the use of any systematic process to guide teachers in the development of their instructional modules or lesson plans, and most programs appear to lack follow-up andlor reports of classroom implementation from the lessons.

Our University has completed one three-year RET program in the area of pharmaceutical engineering and has begun a second. Each participating teacher has been able to enrich his or her own knowledge-base as a STEM education professional as an active member of a research team. Each teacher was able to gain a better understanding of how scientists and engineers engage in research and how the term inquiry is integral to the research process. And finally, each teacher was able to synthesize his or her research experience in order to integrate the acquired content knowledge and skills into a learning module for their students, but preparation of lesson plans is often a challenging experience for teachers, especially when the lessons involve new content they have just learned. Our experience guiding teachers in lesson plan development has shown us that teachers will generally develop instructional strategies first, without realizing the importance of learning objectives for providing direction in the development of lessons and alignment with standards. As a result, for the teacher professional development component of our RET we have developed a systematic process for guiding teachers through the development of their instructional modules including standards-based lesson planning, and aligning the lessons with the Next Generation Science Standards (NGSS).

The current paper is a follow-up study that focuses on the content and classroom implementation of the teachers' instructional modules, a review of the effectiveness of the lesson plans, and an assessment of the student work products as a result of the lessons that demonstrate student acquisition of skills and knowledge specified by the learning objectives and associated studentcentered learning experience.

\section{Introduction}

The Research Experiences for Teachers (RET) program is seen as vehicle for introducing engineering into secondary school curriculum to enhance science and mathematics instruction as well as a strategy that prepares teachers for improving interest and achievement of students in the 
STEM subjects ${ }^{1}$. A RET program was implemented at our university to provide an authentic research experience for high school science and technology/engineering teachers, as part of a research team, within a University research center, and in collaboration with a K-12 Center within the University. The professional development program was designed to provide the high school teachers with the opportunity to enhance their research skills and their knowledge of science and engineering concepts that enables them to integrate cutting-edge science and engineering into their teaching practice through the development of standards-based classroom lessons and learning modules. The program also focused on helping the teachers refine their instructional planning skills and providing them with an effective protocol for developing standards-based lesson plans.

Evaluation tools have been developed and/or adapted to measure the impact of the program on teachers' skills and knowledge, and self-efficacy, as well as classroom impacts on their students' attitudes, skills and knowledge, that have been reported previously ${ }^{2,3}$. While numerous studies have appeared regarding the important features of an effective professional development program, less is known about the specific features that result in improved student achievement ${ }^{4-11}$. It has been generally accepted that effective professional development, that influences classroom practice, would have the following features ${ }^{11}$ :

(a) There is a focus on content knowledge;

(b) There are opportunities for active learning, where teachers can be actively engaged;

(c) It builds on prior knowledge aligned with standards and assessment;

(d) It is of long duration (and not a "one-shot" workshop).

While effective professional development can be linked to improved classroom practice, a direct link to how professional development affects student learning is still lacking. This disconnect between the effects of professional development and student learning may still exist because most reports on teacher professional development programs focus on teacher change and assessment of the direct impacts on teachers, and not the more difficult task of measuring the impact on student learning. Some studies have shown moderate effects on teaching practices and very small but sometimes significant effects on student learning when linked to changes in teaching practices ${ }^{12-13}$. Such studies have been limited to elementary grade levels. Linking professional development and teaching practices to student learning requires actual samples of student work, or "artifacts" to be able to measure student achievement of expected skills and knowledge. The current paper focuses on the link between teachers' acquisition of skills and knowledge from participation in a RET program and its impact on student learning.

Current literature contains numerous reports on other RET programs ${ }^{14-22}$, with varying focus. Many of the programs describe the logistics with some evaluations of the programs by the teachers ${ }^{14-18}$. One paper reported some follow-up of the teachers beyond the summer research experience ${ }^{19}$, another provided brief descriptions of the lessons that resulted from the summer research experience ${ }^{20}$, and a third report uploaded the teacher lessons plans onto their website ${ }^{21}$. However, these lessons were not standards-based and there was no reference to assessment of student learning that could be tied to the professional development program. One program did report the belief that participation in the RET program gave teachers hands-on science experience that helped to motivate student achievement, demonstrated by better scores on New York State science Regents exams than "comparable" non-RET teachers ${ }^{22}$. However, such a comparison does not necessarily link the skills and knowledge gained by the teachers from the professional development program to specific student achievement of skills and knowledge relevant to the RET experience. Better test scores among students of these teachers could be a result of 
their summer research experiences, or the results could mean those teachers are more highly motivated, therefore encouraging their students to perform better in their classes. And it is likely that the more effective teachers are more likely to participate in a RET program.

\section{Standards-Based Lesson Planning}

Our RET program was designed to provide:

1. The teachers with six weeks of discovery-based research experiences in carefully selected projects from which they can develop new knowledge and skills that they can incorporate into their teaching practices.

2. Guidance for the teachers to develop, during their summer internship, age-appropriate lessons, modules and other teaching materials that can be implemented in their classrooms and integrated into the existing curriculum.

Development of the lessons were guided by a process for standards-based lesson planning developed at the Center for Pre-College Programs at New Jersey Institute of Technology, which was introduced to the teachers as a way to systematically assess learning outcomes that are aligned with state and national content standards. The process aligns curriculum, instruction, and assessment to goals for student learning (i.e., learning objectives), an essential first step to achieve alignment with standards ${ }^{23-24}$.

The development of standards-based lesson plans and assessment of student work products resulting from the lesson(s) are meant to be used to determine if students' attain the skills and knowledge specified by the relevant standard(s). Research suggests that lesson and unit plans are essential and powerful tools for instructional improvement and increased student achievement $^{25}$. When teachers prepare truly standards-based lessons, their teaching is focused on student achievement in relation to specific standards. Aligning curriculum, instruction, and assessment to goals for student learning (i.e., learning objectives) is essential. The use of standards-aligned curriculum materials is necessary, but not sufficient for students to achieve the standards ${ }^{24}$. For students to achieve the standards there must be more than just a matching or referencing of topics in a textbook to standards. Alignment with standards must also include the assessment of student achievement of the skills and knowledge defined by the standards. Criteria must be established that allow teachers to determine whether their students have achieved the standard. Standards-based lessons use measurable objectives to assess student learning not just reference standards ${ }^{26}$.

Our process for the creation and implementation of standards-based lesson plans has been utilized in previous and current professional development programs, in addition to the RET programs. In the process, one or more measurable learning objectives are identified for the lesson. For each learning objective the corresponding statement from the content standards is then specified. The lesson is identified, and if necessary modified, to provide students the opportunity to acquire the skill and/or knowledge specified by the learning objective and the appropriate statement of the standards. Performance descriptors are used for the analysis of student behaviors and work products, which provide evidence that the student has acquired the skill and/or knowledge of the learning objective specified by the indicator(s) of the standard(s). The key to the process is the identification of the learning objective(s) for the lesson. The learning objectives should be achievable by students and documented through student work that 
can be evaluated. A synthesis of the behavioral verbs that exemplify Bloom's higher-order learning is critical for assessing mastery of the performance indicators.

\section{Transferring the Research Experience into the Classroom: Student Achievement}

A previous paper reported on a process that guided teachers in the translation of their research experiences into the development of classroom lessons ${ }^{3}$, so that each teacher was able to synthesize his or her research experience in order to integrate the acquired content knowledge and skills into a learning module for the high school students, which supplements the school/district curriculum. The process for guiding the teachers included the following:

- Translation of their research experiences into classroom content, and how they would bring their experiences into the classroom and the classroom experiences they expect to be able to provide to their students.

- Alignment of their lesson plans with standards.

- Development of the lesson plan(s).

A template was created for use in the development of their instructional modules. The "outcomes matrix" was developed as a tool for teachers to organize their thoughts into welldefined learning objectives and student learning outcomes, student-focused learning experience, and assessment strategies (assessment tools, and criterion for levels of mastery), that guides them in the development of their instructional module and lesson plans (Figure 1. The outcomes matrix was designed to show how:

- The learning objectives should be linked to the key concepts, and clearly define what students should know and be able to do at the end of the lesson.

- The learning experience is linked to the learning objectives.

- Assessment of students work products that result from the learning experience should be able to demonstrate that students had or had not acquired the skills and knowledge defined by the learning objectives.

\begin{tabular}{|l|l|l|}
\hline & MODULE & Lesson \\
\hline $\begin{array}{l}\text { Topic Title } \\
\text { Brief Description (one sentence) }\end{array}$ & \\
\hline Learning Objective(s) & & \\
\hline $\begin{array}{l}\text { Learning Experience } \\
\text { (Instructional Plan - Summary) }\end{array}$ & \\
\hline $\begin{array}{l}\text { Student Assessment } \\
\text { (Demonstration of Acquired Skills \& Knowledge) }\end{array}$ & & \\
\hline
\end{tabular}

Figure 1. Outcomes Matrix Template 
Since the publication of prior results, we have found a couple of issues that need further work.

1. Many teachers were not fully grasping the meaning and process of creating a standards-based lesson plan.

2. The focus of the process and assessment remained on the teacher rather than on the student. Our professional development program focused on the assumption that the lesson plan could provide significant information on a teacher's classroom practice, and the impact of the professional development experience on the teacher. In addition, the lesson plan could provide information on how well teachers have acquired the new knowledge and skills and are able to integrate the content into their classroom practice.

Thus, moving forward, the most recent cohort of teachers included several returning teachers invited back for a second summer research experience, and a group of new teacher participants. Thus, there was an opportunity to provide more intensive guidance for the returning teachers in the preparation of lesson plans. In addition, a more detailed discussion on assessment and student work products that focus on student acquisition of skills and knowledge specified in the instructional objectives was added to the professional development component. Some initial results are reported here. Examples of the experiences of two teachers will be described.

Since the research experience is meant to be an intensive, the time needed to provide the workshops for guiding the teachers through the development process and for the teachers to have the time to prepare the lesson plans is not available. The Outcomes Matrix is the deliverable teachers are expected to submit at the end of the summer program. The Outcomes Matrix provides the K-12 Center staff the opportunity to review the teachers' work and engage them in discussion as to the strengths and weaknesses of the content of the Outcomes Matrix. The teachers are expected to use the Outcomes Matrix as they create and implement their lesson plans during the Fall in preparation for a presentation on their lesson plan during a follow-up workshop in December.

Example 1. The following is the submission from a first-time teacher in the RET program. She is a high school chemistry teacher. The research project on which she worked during the summer involved the preparation of numerous solutions, which were then analyzed to measure certain parameters. The topic of her instruction module was "Methods of determining the concentration of soluble compounds or analytes". In the discussion of the protocol for creating a standards-based lesson plan, teachers should become aware that when selecting content standards for the lesson, no more than 3-4 standards should be selected for a lesson, and the standards must be aligned with the instructional objectives and relevant to the learning experience that will be provided for the students. Unfortunately, this teacher's lesson plan missed on both counts. The lesson listed 9 standards, of which 5 were from the Common Core for ELA-Literacy standards, 2 were from the CCSS-Math standards, and 2 were from the Next Generation Science Standards (NGSS), and none of them were aligned with the instructional objectives or relevant to the learning experience, not even the 2 from NGSS. It should be noted that this is not an uncommon response from by teachers exposed to standards-based lesson planning for the first time.

Examination of the two selected science standards finds that neither one is relevant to the lesson (Table 1). Perhaps the standards that best fits the lesson would be 5.PS1-3. 
Table 1

Science Standards indicated in a Teacher's Lesson Plan

\section{Standards Included:}

HS-PS4-4. Evaluate the validity and reliability of claims in published materials of the effects that different frequencies of electromagnetic radiation have when absorbed by matter.

HS-PS4-5. Communicate technical information about how some technological devices use the principles of wave behavior and wave interactions with matter to transmit and capture information and energy.

\section{More Relevant Science Standard:}

5-PS1-3. Make observations and measurements to identify materials based on their properties.

Example 2. This teacher was also a high school chemistry teacher. The topic of his lesson plan was "Surface Area and Solubility". The learning experience would have students study the effect of surface area on the rate of solubility of a substance, "Life Savers" Mints. The surface area would be varied by having the student put the mint into the mouth and measuring the rate of solubility of the mint after:

1. Not chewing or moving the mint around.

2. Moving the tongue around only without chewing.

3. Chewing the mint.

The teacher specified three NGSS standards in his lesson plan:

- HS-N.QA.I. Use units as a way to understand problems and to guide the solution of multistep problems; choose and interpret units consistently in formulas; choose and interpret the scale and the origin in graphs and data displays.

- $\quad$ HSS.1C.B.6 Evaluate reports based on data.

- HS-PS2-6. Communicate scientific and technical information about why the molecularlevel structure is important in the functioning of designed materials.

As in the previous example, the standards do not appear relevant to the instructional objectives of the lesson, which were:

- To conduct an experiment where the surface area is altered, and

- To apply the concept of surface area to solubility and rate of dissolution.

The instructional objectives for the lesson were aligned with the learning experience and with the assessment of student acquisition of skills and knowledge but not with the referenced standards. The assessment plan of the teacher was two-fold.

- "Students will be assessed in their ability to conduct measurements and to infer the effect of surface area to rate of dissolution."

- "Completion of worksheet and answering to questions is part of the activity."

The first part of the assessment plan was good as it was specifically aligned with the objectives and the learning experience. The second part requires completion of a work sheet. The assessment tool is shown in Figure 2. 


\section{Solubility Worksheet}

1. How long did it take each mint to dissolve?

2. Scientifically explain your results. Use the following words in your explanation: Surface area, agitation, chewing, solvent, solute, and solution.

3. Complete the following table:

\begin{tabular}{|l|l|}
\hline Solute & Time (In seconds) \\
\hline Whole mint & \\
\hline Swirled around mint & \\
\hline Chewed mint & \\
\hline
\end{tabular}

\section{Figure 2. Solubility Worksheet}

Figures 3a and 3b show samples of one student's work for this lesson. This sample of student work is clearly in response to the teacher's assessment plan and allows the teacher to measure how well the student has acquired the desired skills and knowledge from the lesson but does not demonstrate learning of the referenced standards..

$$
\begin{aligned}
& 7 \text { seconds for the swirted around } \\
& \text { tissolved. } \\
& \text { face area of the mint was large which } \\
& \text { itating it difficult. Chewing the mint was } \\
& \text { way in breaking down the solutinesund } \\
& \text { hen you chew the mint it becomos } \\
& \text { d makes it easier to mix in with } \\
& \text { it. (salival and making the solution. } \\
& \text { Solid is dissolved into a liquid it's } \\
& \text { a solution. It takes tome to dissolve } \\
& \text { " but it can be faster. The greater } \\
& \text { int of the surface area is exposed } \\
& \text { solvent, the faster the solute will } \\
& \text { he dissolving procieres is also } \\
& \text { 'by the amount of stifing } \\
& \text { ne thent is done. By chawing on } \\
& \text { t, you ane minimizing the susfac } \\
& \text { ad making it easier for it to }
\end{aligned}
$$

Figure 3a. Part 1 of Student Work Product from Lesson in Example 2. 


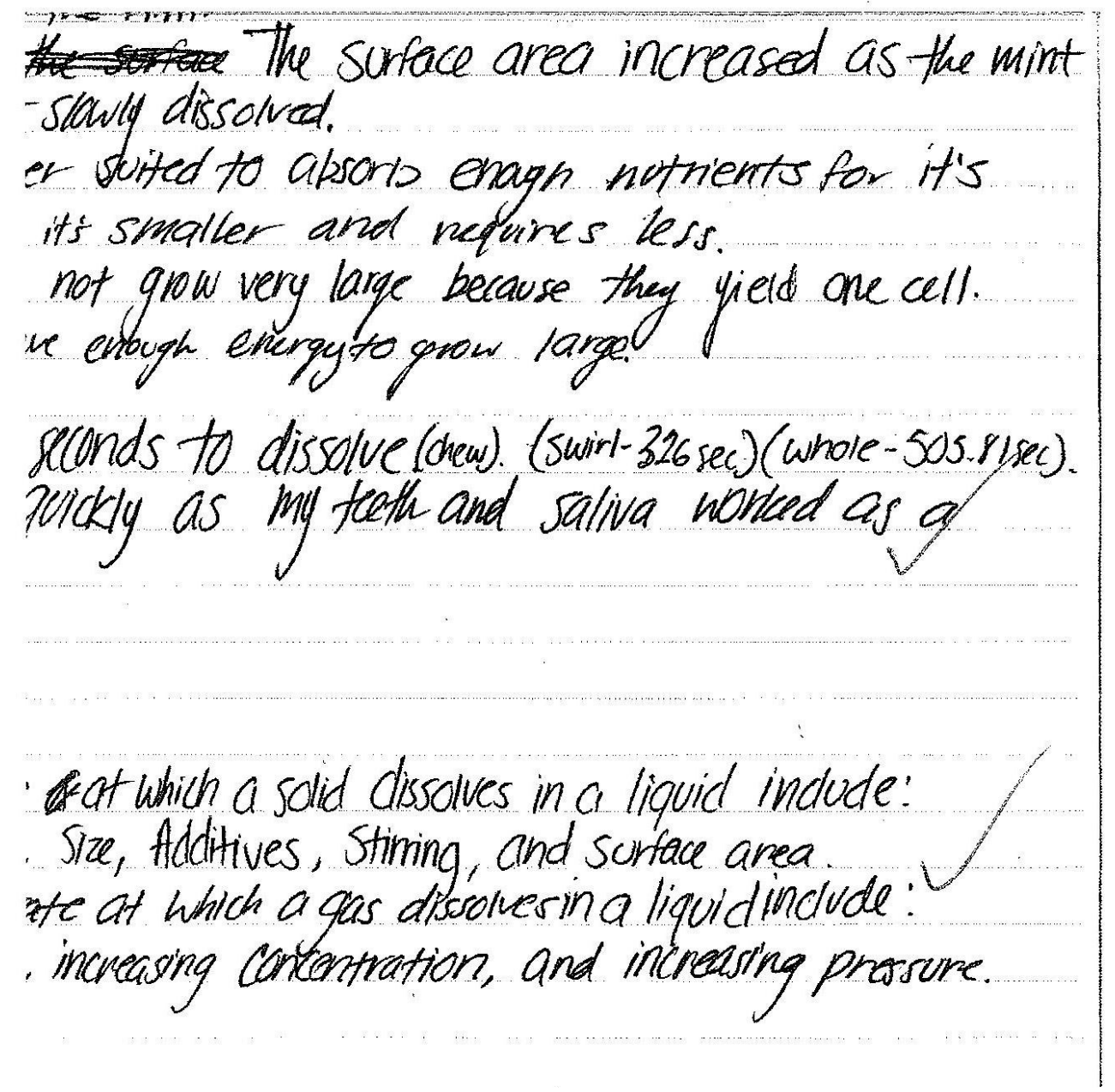

Figure 3b. Part 2 of Student Work Product from Lesson in Example 2.

\section{Conclusion}

Teachers need more guidance in standard-based lesson plan development. The examples shown are typical of the results when teachers develop instructional strategies first, without realizing the importance of learning objectives aligned with specific standards. Students may demonstrate learning of the skills and knowledge as intended by the teacher and captured in the assessment but that is not necessarily attainment of the standards if the learning objectives are not properly aligned with the referenced standards.

Not all teachers in the last RET cohort were willing to provide their completed "standards-based lesson plans and examples of student work to date, but the examples provided are typical. Future work will focus on providing feedback and further instruction to these teachers and revising the content and presentation of professional development workshops on standards-based lesson planning to provide more effective instruction for future teachers. 


\section{Acknowledgement}

The authors would like to acknowledge the financial support provided by the U.S. National Science Foundation under award number 1301071. Any opinions, findings, and conclusions or recommendations expressed in this material are those of the authors and do not necessarily reflect the views of the National Science Foundation.

\section{Bibliography}

[1] Russell, S. H., and Hancock, M. P. (2006). Evaluation of the Research Experiences for Teachers (RET) Program. Menlo Park, CA:SRI International.

[2] Kimmel, H., Hirsch, L. S., Simon, L., Burr-Alexander, L. and Dave, R. (2009). Implementing Concepts Of Pharmaceutical Engineering Into High School Science Classrooms. Chemical Engineering Education, 43 (3), 187 193.

[3] Carpinelli, J., Kimmel, H., Hirsch, L. S., Burr-Alexander, L., Nahr, K. and Dave, R. (2011). Translating Research Experiences into Classroom Practice: An RET Project," Proceedings of the 2011 ASEE Annual Conference, Vancouver, CA, June.

[4] Guskey, T. (1986). Staff Development and the Process of Teacher Change. Educational Researcher, 15, 5-12. [5] Showers, B., Joyce, B, and Bennett, B. (1987). Synthesis of Research on Staff Development: A Framework for Future Study and a State-of-the-Art Analysis. Educational Leadership, 45 (3), 77-88.

[6] Guskey, T. and Sparks, D. (1991). What to Consider When Evaluating Staff Development. Educational Leadership, 49 (3), 73-76.

[7] Guskey, T. (2002). Does It Make A Difference? Evaluating Professional Development. Educational Leadership, 59 (6), 45-51.

[8] Guskey, T. (2003). What Makes Professional Development Effective? Phi Delta Kappan, 84 (10), 748-750.

[9] Kelleher, J. (2003).A Model for Assessment-Driven Professional Development. Phi Delta Kappan, 84 (10), 751756.

[10] Borko, H. (2004). Professional Development and Teacher Learning: Mapping the Terrain. Educational Researcher, 33, 3-15.

[11] Yoon, K.S., M. Garet, B. Birman, and R. Jacobson, Examining the Effects of Mathematics and Science Professional Development on Teachers' Instructional Practice: Using Professional Development Activity Log, Council of Chief State School Officers, Washington, DC (2006).

[12] Yoon, K. S., Duncan, T., Lee, S. W.-Y., Scarloss, B., \& Shapley, K. (2007). Reviewing the evidence on how teacher professional development affects student achievement, REL 2007-No. 033. Washington, DC: U.S. Department of Education, Institute of Education Sciences, National Center for Education Evaluation and Regional Assistance, Regional Educational Laboratory Southwest. Retrieved from http://ies.ed.gov/ncee/edlabs.

[13] Desimone, L., Smith, T. M., and Phillips, K., J., R. (2013). Linking Student Achievement Growth to Professional Development Participation and Changes in Instruction: A Longitudinal Study of Elementary Students and Teachers in Title I Schools. Teachers College Record, 115 (5), 1-46. Retrieved from http://www.tcrecord.org. [14] Miller, B., and Winter, R. M. (2006) RET Site: Inspiring Educators in Rural America through Research. 2006 AIChE Annual Meeting Conference Proceedings. New York, NY.

[15] Bearden, K. K., Mainardi, D. S., and Culligan, T. (2009). In Search of the Active Site of pMMO Enzyme: Partnership Between a K-12 Teacher, a Graduate K-12 Teaching Fellow, and a Research Mentor. Chemical Engineering Education, 43 (4), 273-278.

[16] Kapila, V. (2010). Research Experience for Teachers Site: A Professional Development Project for Teachers. Proceedings of the 2010 ASEE Annual Conference,. Louisville, KY, June.

[17] Benson, L., Medders, E., and Cass, C. (2010). Teachers as Scientists: A Qualitative Study of Outcomes for an RET Program. Proceedings of the 2010 ASEE Annual Conference, Louisville, KY, June.

[18] High, K., Utley, J., and Angle, J. (2012). The Effect of University Research Experiences on Middle Level Math and Science Instructors Perceptions. Proceedings of the 42th ASEE/IEEE Frontiers in Education Conference, Seattle, WA, October. 
[19] Conrad, L., Conrad, E., and Auerbach, J. (2007) The Development, Implementation, and Assessment of an Engineering Research Experience for Physics Teachers. Proceedings of the 2007 ASEE Annual Conference,

Honolulu, June.

[20] Laffey, E. H., Cook-Chennault, K., and Hirsch, L. S. (2012). RU RET-E: Designing and Implementing

Engineering-Based Lessons for the Pre-College Classroom. Proceedings of the 2012 ASEE Annual Conference,. San Antonio, TX, June.

[21] Orlich, D., Zollers, R., and Thomson, W. (2006). Introducing Engineering at the Middle School and High School Level," Proceedings of the 2006 ASEE Annual Conference, Chicago, June.

[22] Silverstein, S. C.,Dubner, J., Miller, J., Glied, S., and Loike, J. D. (2009). Teachers' Participation in Research Programs Improves Their Students' Achievement in Science. Science, 326, 440-443 (October 16).

[23] Kimmel, H. and O'Shea, M. (1999). Professional Development and the Implementation of Standards, Proceedings of the 29th ASEE/IEEE Frontiers in Education Conference, San Juan, PR, November. [24] O’Shea, M. and Kimmel, H. (2003) Preparing Teachers for Content Standards: A Field Study of Implementation Problems, Proceedings of the American Association for Colleges of Teacher Education, New Orleans, LA, January.

[25] Tell, C.A., Bodone, F. M., and Addie, K. L. (2000). A Framework of Teacher Knowledge and Skills Necessary in a Standards-Based System: Lessons from High School and University Faculty, Annual Meeting of the American Educational Research Association, New Orleans, LA, April.

[26] Rothman, R., Slattery, J. B., Vranek, J. L., and Resnick, L. B. (2002) Benchmarking and Alignment of Standards and Testing, CSE Technical Report 566, Los Angeles, CA: National Center for Research on Evaluation, Standards, and Student Testing, UCLA. 